\section{(6) OPEN ACCESS}

- An additional data is published online only. To view this file please visit the journal online (http://dx.doi.org/ 10.1136/bjsports-2012-091258)

${ }^{1}$ Department of Sports Medicine, ASPETAR, Oatar Orthopaedic and Sports Medicine Hospital, Doha, Oatar ${ }^{2}$ Research Institute for Sport and Exercise Science, Liverpool John Moores University, Liverpool, Merseyside, UK ${ }^{3}$ Department of Heart Muscle Disorders and Sports Cardiology, St Georges Hospital, London, UK

${ }^{4}$ Rennes 1 University, Pontchaillou Hospital, INSERM UMR 1099, Rennes, France ${ }^{5}$ St Vincent's University Hospital and The Blackrock Clinic, Dublin, Ireland ${ }^{6}$ Centre for Sports Cardiology, Centre for Health and Human Performance, London, UK

\section{Correspondence to} Dr Mathew Wilson, ASPETAR, Oatar Orthopaedic and Sports Medicine Hospital, PO Box 29222, Doha, Oatar; mathew. wilson@aspetar.com

Received 8 April 2012 Accepted 10 July 2012

\title{
Do big athletes have big hearts? Impact of extreme anthropometry upon cardiac hypertrophy in professional male athletes
}

\author{
Nathan R Riding, ${ }^{1,2}$ Othman Salah, ${ }^{1}$ Sanjay Sharma, ${ }^{3}$ François Carré, ${ }^{4}$ Rory O'Hanlon, ${ }^{5}$ \\ Keith P George, ${ }^{2}$ Bruce Hamilton, ${ }^{1}$ Hakim Chalabi, ${ }^{1}$ \\ Gregory P Whyte, ${ }^{2,6}$ Mathew G Wilson ${ }^{1}$
}

\section{ABSTRACT}

Aim Differentiating physiological cardiac hypertrophy from pathology is challenging when the athlete presents with extreme anthropometry. While upper normal limits exist for maximal left ventricular (LV) wall thickness $(14 \mathrm{~mm})$ and LV internal diameter in diastole (LVIDd, $65 \mathrm{~mm})$, it is unknown if these limits are applicable to athletes with a body surface area (BSA) $>2.3 \mathrm{~m}^{2}$.

Purpose To investigate cardiac structure in professional male athletes with a BSA $>2.3 \mathrm{~m}^{2}$, and to assess the validity of established upper normal limits for physiological cardiac hypertrophy.

Methods 836 asymptomatic athletes without a family history of sudden death underwent ECG and echocardiographic screening. Athletes were grouped according to BSA (Group 1, BSA $>2.3 \mathrm{~m}^{2}, \mathrm{n}=100$; Group 2, 2-2.29 m², $\mathrm{n}=244$; Group 3, <1.99 m², n=492).

Results There was strong linear relationship between BSA and LV dimensions; yet no athlete with a normal ECG presented a maximal wall thickness and LVIDd greater than 13 and $65 \mathrm{~mm}$, respectively. In Group 3 athletes, Black African ethnicity was associated with larger cardiac dimensions than either Caucasian or West Asian ethnicity. Three athletes were diagnosed with a cardiomyopathy (0.4\% prevalence); with two athletes presenting a maximal wall thickness $>13 \mathrm{~mm}$, but in combination with an abnormal ECG suspicious of an inherited cardiac disease. Conclusion Regardless of extreme anthropometry, established upper limits for physiological cardiac hypertrophy of $14 \mathrm{~mm}$ for maximal wall thickness and $65 \mathrm{~mm}$ for LVIDd are clinically appropriate for all athletes. However, the abnormal ECG is key to diagnosis and guides follow-up, particularly when cardiac dimensions are within accepted limits.

\section{INTRODUCTION}

Regular and prolonged intensive exercise is associated with cardiac morphological adaptation, together with electrocardiographic alterations. ${ }^{1-4}$ Significant cardiac enlargement may be an expression of underlying cardiac disease, placing the athlete at a greater risk of sudden cardiac death (SCD). ${ }^{5}$ In rare cases, the degree of physiological adaptation in cardiac morphology can mimic that of a number of pathological disease states, most notably hypertrophic cardiomyopathy (HCM). ${ }^{6}$ Differentiation between a physiological or pathological remodelling process is, therefore, extremely important. Consequently, establishing the upper normal limits of physiological enlargement in response to physical training is an important focus for clinicians and scientists.

Fourteen and $65 \mathrm{~mm}$ have been established as the physiological upper limits for maximal wall thickness and left ventricular (LV) internal diameter during diastole, respectively. These limits come from three large-scale studies examining approximately 4800 elite athletes (predominantly male), who observed that a small minority (1.5-4\%) demonstrate LV hypertrophy (LVH) $>13 \mathrm{~mm}$ and $4-6 \%$ have an LV end-diastolic dimension $>60 \mathrm{~mm}$. What this minority of athletes with pronounced LVH have common is an enlarged BSA (approximate mean BSA $\left.2.1 \mathrm{~m}^{2}\right) .{ }^{4} 78$ However, despite recognising that the largest maximal wall thicknesses are observed in those with the largest BSA's, there are limited data examining the impact of extreme body anthropometry (BSA $\left.>2.3 \mathrm{~m}^{2}\right)$ upon cardiac morphology in professional athletes. This is important as it is widely recognised that LV dimensions are influenced by body anthropometry. ${ }^{9} 10$ Pluim et $a l^{2}$ was the first to recognise the importance of BSA when undertaking preparticipation screening, suggesting that the probability of falsepositive HCM identification would be exacerbated in athletes with a BSA $>2 \mathrm{~m}^{2}$. Basketball, handball and volleyball are three such sports whereby some male athletes may exceed the stereotypical anthropometry for an athlete; with heights and body mass's reaching $220 \mathrm{~cm}$ and $150 \mathrm{~kg}$, respectively. ${ }^{11} 12$ Magalski et al ${ }^{13}$ electrocardiographic examination of 1959 American Football players was one of the largest studies to undertake preparticipation screening in athletes with large anthropometry (mean BSA; $2.4 \pm 0.3 \mathrm{~m}^{2}$ ). Regrettably, only 203 American Football players received an echocardiogram following a referral due to an abnormal ECG, family history or clinical examination, with the BSA of this cohort unreported.

The aim of the present study was to investigate the cardiac structure and function in professional male athletes with extreme anthropometry $\left(\geq 2.3 \mathrm{~m}^{2}\right)$, to confirm if the established upper limits of physiological cardiac adaptation to intensive and sustained physical activity are applicable for this unique population.

\section{METHODS}

Ethical approval was obtained from the Shafallah Medical Genetics Centre ethics committee, with all athletes completing informed consent. 


\section{Participants}

836 asymptomatic professional male athletes (age $25 \pm 8$ years), exercising $\geq 6 \mathrm{~h} /$ week in 15 high-intensity intermittent sporting disciplines (eg, Soccer, $\mathrm{n}=586$; basketball, $\mathrm{n}=75$; volleyball, $\mathrm{n}=41$ and handball, $\mathrm{n}=35$ ) presented at our institution for preparticipation cardiac screening (table 1). Athletes were categorised into three distinct groups according to their body surface area $^{14}$ (DuBois and DuBois, 1916); Group 1 BSA $>2.3 \mathrm{~m}^{2}(\mathrm{n}=100,197 \pm 9 \mathrm{~cm}$ and $105 \pm 12 \mathrm{~kg})$; Group 2 BSA $2-2.29 \mathrm{~m}^{2}(\mathrm{n}=244,184 \pm 6 \mathrm{~cm}$ and $83 \pm 6 \mathrm{~kg})$ and Group 3 $\mathrm{BSA}<1.99 \mathrm{~m}^{2}(\mathrm{n}=492,172 \pm 6 \mathrm{~cm}$ and $66 \pm 8 \mathrm{~kg})$. Strict exclusion criteria included athletes who had undergone previous preparticipation cardiovascular screening with electrocardiography and echocardiography, and those athletes currently experiencing symptoms suggestive of cardiovascular disease and/or demonstrating an early family history of SCD. This was important as the population truly reflected those individuals who had not been excluded from competitive sport on the suspicion of harbouring an inherited cardiac pathology. As previously described, ${ }^{15} 16$ the term 'West-Asian' denotes individuals of Gulf or Middle-Eastern descent, and 'Black African' denotes individuals of African descent. West-Asian athletes were recruited from seven Gulf States (Qatar, Bahrain, Oman, UAE, Kuwait, Yemen and Saudi Arabia) and six Middle-Eastern countries (Egypt, Jordan, Palestine, Iraq and Lebanon). Black athletes from seven African countries (Sudan, Somalia, Ghana, Nigeria, Ivory Coast Senegal, Cameroon and Ethiopia) were also recruited alongside Caucasian athletes from the USA, Canada, Australia, Russia, Bosnia and Croatia.

\section{Physical examination}

The physical examination was based on the European Society of Cardiology (ESC) sport's cardiology section consensus statement. ${ }^{11}$ Players completed the questionnaire regarding family history and personal symptoms in collaboration with an Arabic-speaking, French-speaking or English-speaking Sports

Table 1 Demographic data of all athletes categorised by body surface area (BSA)

\begin{tabular}{|c|c|c|c|}
\hline & Group 1 & Group 2 & Group 3 \\
\hline & $\begin{array}{l}\text { BSA }>2.3 \mathrm{~m}^{2} \\
(\mathrm{n}=99)\end{array}$ & $\begin{array}{l}\text { BSA 2-2.29 } \mathrm{m}^{2} \\
(\mathrm{n}=244)\end{array}$ & $\begin{array}{l}\text { BSA }<1.99 \mathrm{~m}^{2} \\
(\mathrm{n}=492)\end{array}$ \\
\hline Age (years) & $\begin{array}{l}26.0 \pm 5.8 \\
(15-35)\end{array}$ & $\begin{array}{l}25.1 \pm 6.2 \\
(14-35)\end{array}$ & $\begin{array}{l}23.5 \pm 6.2^{* * *} \\
(13-37)\end{array}$ \\
\hline Height $(\mathrm{cm})$ & $\begin{array}{l}196.8 \pm 8.6^{*} \\
(170-217)\end{array}$ & $\begin{array}{l}183.7 \pm 6.2^{* *} \\
(168-207)\end{array}$ & $\begin{array}{l}172.5 \pm 7.6 \\
(153-191)\end{array}$ \\
\hline Weight $(\mathrm{kg})$ & $\begin{array}{l}105.1 \pm 12.1^{*} \\
(85-156)\end{array}$ & $\begin{array}{l}82.8 \pm 5.9^{* *} \\
(66-110)\end{array}$ & $\begin{array}{l}66.2 \pm 7.5 \\
(41-88)\end{array}$ \\
\hline \multicolumn{4}{|l|}{ Ethnicity (\%) } \\
\hline West-Asian & 31 & 55 & 76 \\
\hline $\begin{array}{l}\text { Black } \\
\text { African }\end{array}$ & 46 & 35 & 19 \\
\hline Caucasian & 23 & 10 & 5 \\
\hline \multicolumn{4}{|l|}{ Sport (\%) } \\
\hline Football & 11.1 & 68.6 & 83.0 \\
\hline Basketball & 40.4 & 8.7 & 2.6 \\
\hline Handball & 18.2 & 7.0 & 0.8 \\
\hline Volleyball & 23.2 & 7.4 & 0.0 \\
\hline Other & 7.1 & 8.3 & 13.4 \\
\hline
\end{tabular}

*Significant difference between BSA $>2.3 \mathrm{~m}^{2}$ and other two groups $(\mathrm{p}<0.05)$.

${ }^{*}$ Significant difference between BSA $2-2.29 \mathrm{~m}^{2}$ and BSA $<1.99 \mathrm{~m}^{2}(\mathrm{p}<0.05)$.

${ }^{* * *}$ Significant difference between both BSA $>2.3 \mathrm{~m}^{2}$ and BSA $2-2.29 \mathrm{~m}^{2}$ from $\mathrm{BSA}<1.99 \mathrm{~m}^{2}(\mathrm{p}<0.05)$.
Medicine Physician and Nurse. Measurement of height (SECA 264, Hamburg, Germany), body mass (Detecto 6129KGM, Missouri, USA), brachial artery blood pressure (GE Dinamap Pro 400V2, New York, USA) in the supine position (both left and right arms) after a period of 5 min rest, precordial auscultation in supine and standing positions, and assessment for any physical characteristics of Marfan's syndrome were undertaken by a Sports Medicine Physician.

\section{Resting 12-lead ECG}

A standard 12-lead ECG was obtained using a GE Mac 5500 (New York, USA) after a period of 5 min rest in the supine position. All ECG's were reported independently by two experienced investigators (OS and MW) using the recent 2010 ESC recommendations for interpretation of 12-lead electrocardiogram in the athlete, ${ }^{17}$ with third opinions sought from two international cardiologists (SS and FC) for difficult cases.

\section{Echocardiography}

A two-dimensional (2D), M-mode and Doppler and tissue Doppler echocardiographic examination was performed in the left lateral decubitas position by a consultant cardiologist using a commercially available ultrasound system (Philips, USA). Images of the heart were obtained in the standard parasternal long-axis and short-axis and apical four-chamber planes, as previously described, ${ }^{18}$ in order to identify subtle focal regions of abnormal LV hypertrophy. The LV wall thickness was measured from 2D short-axis views in end-diastole, with the greatest measurement within the LV wall defined as the maximal wall thickness. M-mode echocardiograms derived from 2D images in the parasternal long axis were used for the measurement of LV end-diastolic diameter (LVIDd) and LV end-systolic (LVIDs) dimensions, left atrial diameter and aortic root diameter according to American Society of Echocardiography standards, ${ }^{19}$ with LV volumes (diastolic and systolic) derived using Simpson's biplane methodology. Left ventricular mass was calculated using the formula of Devereux. ${ }^{20}$ Three to five consecutive measurements were taken, and the average was calculated. Left ventricular diastolic function was assessed using pulsed-wave Doppler recordings from apical four-chamber orientations. A $4 \mathrm{~mm}$ sample volume was placed at the tips of the mitral leaflets in diastole and transmitral flow was acquired to obtain peak early (E) and atrial (A) flow velocities. All data was analysed offline and a minimum of three cardiac cycles were averaged for all indices. For the tissue Doppler assessment of E', the apical four-chamber orientation was utilised and a $2 \mathrm{~mm}$ sample volume was positioned at both the septal and lateral wall aspect of the mitral valve annulus ensuring the best alignment between wall motion and the ultrasound beam. The high-pass filter was bypassed and gains set to a minimal value to obtain the best signal-to-noise ratio. The nyquist limit was set between 10 and $35 \mathrm{~cm} / \mathrm{s}$. Peak early diastolic (E') tissue myocardial velocity was recorded and E/E' was calculated.

\section{Criteria for consideration of the diagnosis of pathological LVH in athletes}

On the basis of previous publications and our own experience of an athlete's heart, athletes with an LV wall thickness $>12 \mathrm{~mm}$ were considered to have LVH. ${ }^{7} 2122$ Athletes with LVH and a relatively non-dilated $\mathrm{LV}$ in terms of athletic training $(<56 \mathrm{~mm})^{23}$ in association with any one of the following were considered to have findings that could be consistent with pathological LVH rather than physiological hypertrophy: (1) impaired diastolic function; ${ }^{24}(2)$ enlarged left atrial diameter $>45 \mathrm{~mm}$ in athletes 
$<18$-year-old ${ }^{25}$ and up to $50 \mathrm{~mm}$ in older athletes; ${ }^{26}$ (3) LV outflow obstruction; ${ }^{27}$ (4) left bundle branch block ${ }^{28}$ and (5) ST-segment depression or deep Twave inversions $(<-0.2 \mathrm{mV})$ in $\geq 2$ contiguous anterior, inferior or lateral leads (but not aVR, and III ${ }^{29}$ on the ECG. Athletes demonstrating echocardiographic and/or ECG abnormalities considered to represent pathological LVH were investigated further with $48 \mathrm{~h} \mathrm{ECG},{ }^{30}$ cardiopulmonary exercise test ${ }^{31} 32$ and cardiac $\mathrm{MRI}^{33}$ to evaluate the broader phenotype of common cardiomyopathic processes such as HCM and arrhythmogenic right ventricular cardiomyopathy, in addition to assessing the risk of SCD. ${ }^{34}$

\section{Statistical analysis}

All data were presented as mean \pm SD and (range), and analysed using SPSS (Statistical Package for Social Sciences 17, Illinois, USA). Data were analysed using a two-way between-subjects analysis of variance, with pair-wise comparisons, used to identify any significant differences in athlete anthropometrics and echocardiographic characteristics between the three BSA groups, together with athlete anthropometrics and echocardiographic characteristics between Black African, West-Asian and Caucasian ethnicity in the $>2.3 \mathrm{~m}^{2}$ BSA group. Relationships between data indices of echocardiographic measures of cardiac structure and function against the athletes BSA together with their resting systolic blood pressure were examined via Pearson's product-moment correlation analysis. A p value $<0.05$ was considered significant.

\section{RESULTS}

None of the athletes experienced angina, breathlessness disproportionate to the amount of exercise performed, or exertional syncope. The diagnosis of HCM was excluded by echocardiography in 819 (98\%) on the basis of an LV wall thickness $<12 \mathrm{~mm}$, absence of systolic anterior motion of the anterior mitral valve leaflet causing LV outflow obstruction and normal diastolic function.

\section{Athletes with an LV wall thickness $>\mathbf{1 2} \mathbf{~ m m ~ ( L V H ) ~}$}

Of the 836 athletes, 17 (2\%) showed a maximal LV wall thickness exceeding $12 \mathrm{~mm}$ and were considered to have $\mathrm{LVH}^{23}$ Twelve $(12 \%)$ of these athletes demonstrating LVH came from the $>2.3 \mathrm{~m}^{2}$ BSA cohort, compared with just $3(1.2 \%)$ and 2 $(0.4 \%)$ from Groups 2 and 3, respectively. All 17 athletes with LVH had an appropriate $(\geq 45 \mathrm{~mm}$ ) LV chamber dimension (mean $56 \pm 4 \mathrm{~mm}$, (range 49-63)), normal systolic and diastolic function, an enlarged left atrial diameter and no systolic anterior motion of the anterior mitral valve leaflet or LV outflow obstruction.

\section{Athletes with an LVH $>\mathbf{1 2} \mathbf{~ m m}$ and an abnormal ECG}

Of the 17 athletes with LVH, only $2(0.2 \%)$ demonstrated a wall thickness that exceeded $13 \mathrm{~mm}$ (table 2; athletes 1 and 2). However, both athletes also demonstrated ECG's highly suspicious of HCM (figure 1A,B). Following extensive further investigation, both athletes were diagnosed with a cardiomyopathy and were eventually disqualified from competitive sport. Both athletes were removed from any further group analysis.

\section{Athletes with other cardiac abnormalities on ECG and echocardiography}

One further athlete (table 2; athlete 3) was diagnosed with a mild variant of apical HCM, due to disproportionally thickened apical segments of the basal and septal walls upon cardiac MRI, following an abnormal ECG (figure 1C) but normal echocardiogram (maximal basal LV wall thickness of $8 \mathrm{~mm}$ ). This athlete was removed from any further group analysis. Four asymptomatic athletes without cardiac murmur were found to have trivial valve regurgitation (one mitral, one aortic and two tricuspid), not requiring further investigation after echocardiography. Finally, one asymptomatic player had an aortic root

Table 2 Follow-up results of three athletes presenting with an abnormal ECG on initial screening

\begin{tabular}{|c|c|c|c|c|c|c|c|c|}
\hline Athlete & Symptoms & $\begin{array}{l}\text { FH of SCD } \\
\text { (<35 year) }\end{array}$ & ECG abnormality & Echocardiogram & $\begin{array}{l}\text { Exercise Stress } \\
\text { Test and } 24 \text { h } \\
\text { Holter ECG }\end{array}$ & CMR & $\begin{array}{l}\text { Screened } \\
\text { first-degree } \\
\text { relatives }\end{array}$ & Diagnosis \\
\hline $\begin{array}{l}\text { (1) 19-year-old } \\
\text { West-Asian } \\
\text { footballer }\left(1.99 \mathrm{~m}^{2}\right. \\
\text { BSA) }\end{array}$ & No & No & $\begin{array}{l}\text { RAE, profound } \\
\text { voltage ( } 77 \mathrm{~mm} \text { ), } \\
0 \text { waves in II, III, } \\
\text { aVF, T wave } \\
\text { inversion in I, II, } \\
\text { III, aVL, aVF and } \\
\text { ST segment } \\
\text { depression in II, } \\
\text { III and aVF }\end{array}$ & $\begin{array}{l}\text { Subaortic IVSd } \\
\text { bulge of } 20 \mathrm{~mm} \text {, } \\
\text { without obstruction } \\
\text { of the outflow tract }\end{array}$ & $\begin{array}{l}\text { No arrhythmia } \\
\text { during exercise } \\
\text { with appropriate } \\
\text { BP response. Few } \\
\text { monomorphic PVB } \\
\text { on Holter } \\
\text { monitoring }\end{array}$ & $\begin{array}{l}\text { Asymmetric septal } \\
\text { hypertrophy with a } \\
\text { maximal septal wall } \\
\text { thickness of } 20 \mathrm{~mm} \\
\text { versus lateral wall of } \\
11 \mathrm{~mm} \text { without } \\
\text { obstruction. No LGE, } \\
\text { oedema or systolic } \\
\text { dysfunction }\end{array}$ & $\begin{array}{l}\text { Father's ECG } \\
\text { and Echo } \\
\text { confirmed } \\
\text { HCM }\end{array}$ & $\begin{array}{l}\text { Non-obstructive } \\
\text { HCM }\end{array}$ \\
\hline $\begin{array}{l}\text { (2) } 29 \text {-year-old } \\
\text { Black } \\
\text { African-American } \\
\text { basketball player } \\
\left(2.35 \mathrm{~m}^{2} \mathrm{BSA}\right)\end{array}$ & No & No & $\begin{array}{l}\text { Profound voltage } \\
\text { in V3, deep T } \\
\text { wave inversion in } \\
\text { V6 }\end{array}$ & $\begin{array}{l}\text { Normal apart from } \\
\text { max wall thickness } \\
\text { of } 13.6 \mathrm{~mm}\end{array}$ & $\begin{array}{l}\text { No arrhythmia } \\
\text { during exercise } \\
\text { with appropriate } \\
\text { BP response } \\
\text { No arrhythmia on } \\
\text { Holter }\end{array}$ & $\begin{array}{l}\text { Mild asymmetric } \\
\text { hypertrophy of IVSd } \\
\text { without obstruction } \\
\text { (basal } 8 \mathrm{~mm} \text {, mid } \\
15 \mathrm{~mm} \text {, apical } 9 \mathrm{~mm} \text { ), } \\
\text { associated with } \\
\text { significant mid-septum } \\
\text { transmural fibrosis }\end{array}$ & Not available & $\begin{array}{l}\text { Non-obstructive } \\
\text { HCM }\end{array}$ \\
\hline $\begin{array}{l}\text { (3) 27-year-old } \\
\text { West-Asian Futsal } \\
\text { player }\left(1.75 \mathrm{~m}^{2}\right. \\
\text { BSA) }\end{array}$ & No & No & $\begin{array}{l}\text { Profound voltage } \\
\text { in V4 (59 mm), T } \\
\text { wave inversion in } \\
\text { II, III, aVF, V2-V6 } \\
\text { and ST segment } \\
\text { depression in } \\
\text { V4-V5 }\end{array}$ & $\begin{array}{l}\text { Normal (max wall } \\
\text { thickness } 8.2 \mathrm{~mm} \text { ) }\end{array}$ & $\begin{array}{l}\text { No arrhythmia } \\
\text { during exercise } \\
\text { with appropriate } \\
\text { BP response } \\
\text { No arrhythmia on } \\
\text { Holter }\end{array}$ & $\begin{array}{l}\text { Apical segments are } \\
\text { disproportionally } \\
\text { thickened, increased } \\
\text { basal and septal wall } \\
\text { thickness. No LGE, } \\
\text { oedema or systolic } \\
\text { dysfunction }\end{array}$ & Not available & $\begin{array}{l}\text { Mild variant of } \\
\text { apical HCM }\end{array}$ \\
\hline
\end{tabular}


dimension at the upper limit of normal but given the borderline measure and normality of other parameters, was provided medical clearance and requested to attend yearly echocardiographic examination. These last five athletes remained in the group analysis.

\section{Impact of BSA upon cardiac structure and function}

A significant and progressive increase in aortic, left and right atrial, as well as left and right ventricular dimensions and volumes was observed as BSA increased (table $3 ; \mathrm{p}<0.05$ ). No athlete with a normal ECG demonstrated a maximal wall thickness $>13 \mathrm{~mm}$ and an LVIDd $>65 \mathrm{~mm}$. A total of 36 athletes (4\% overall) had an LVIDd $>60 \mathrm{~mm}$; of which $19(19 \%)$ came from Group 1 compared to 13 (5\%) and 4 (0.8\%) from Groups 2 and 3, respectively. A significantly higher peak early diastolic mitral flow velocity was observed in Group 3 compared to the two other BSA groups $(p<0.05)$. Furthermore, a peak early mitral annular velocity of the septal wall was significantly lower in Group 1 athletes than the other two BSA groups $(p<0.05)$. No other cardiac functional measures were significantly different between BSA groups. Finally, a significant linear relationship $(r=0.3, p<0.0001)$ was observed between the athletes BSA and their systolic blood pressure (figure 2), and between systolic blood pressure and IVSd $(r=0.49)$, LVIDd $(r=0.54)$, posterior wall thickness in diastole (PWTd) $(r=0.51)$ and $\operatorname{LVM}(\mathrm{r}=0.69, \mathrm{p}<0.0001)$.

\section{Impact of ethnicity upon cardiac structure and function in athletes with a BSA $>2.3 \mathrm{~m}^{2}$}

Of the 99 remaining athletes in the BSA>2.3 $\mathrm{m}^{2}$ cohort (31 West-Asian, 45 Black African and 23 Caucasian athletes), there were no significant differences in BSA between the three ethnicities. Black African athletes had a significantly thicker IVSd and PWTd than both West-Asian and Caucasian athletes $(p<0.05)$. Black African athletes also had significantly larger LA volumes, RA areas and LV masses than West-Asian athletes $(p<0.05)$. West-Asian athletes had a significantly larger LVIDd than Caucasian athletes $(p<0.05)$. There were no significant differences between ethnicities in any diastolic or systolic parameter (table 4).

\section{DISCUSSION}

The main finding of the current study was that the upper normal limits for maximal LV dimensions in professional male athletes with extreme anthropometric characteristics $\left(\mathrm{BSA}>2.3 \mathrm{~m}^{2}\right.$ ) remains $14 \mathrm{~mm}$ for maximal wall thickness and $65 \mathrm{~mm}$ for LV internal diameter during diastole. Furthermore,
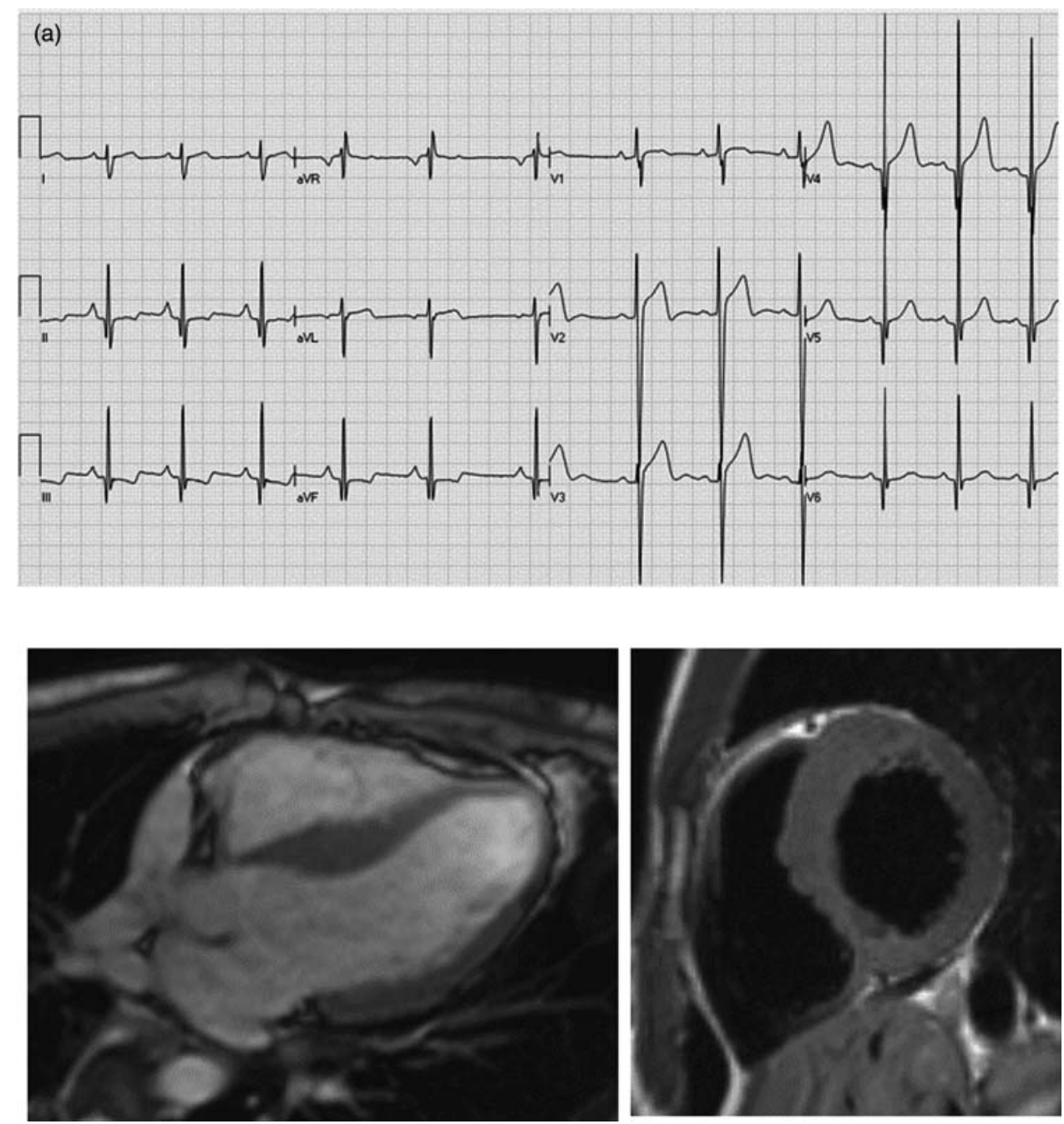

Figure 1 (A)-(C) Twelve-lead ECG and cardiac magnetic resonance images of two athletes (1 and 2) with a maximal wall thickness greater than $13 \mathrm{~mm}$, and one athlete (3) with a maximal wall thickness of $8.2 \mathrm{~mm}$ on echocardiography, yet apical segments do not show normal tapering pattern and are disproportionately thickened on CMR imaging. Arrow (athlete 2) points to localised fibrosis of the septal wall at the mid-cavity level. This figure is only reproduced in colour in the online version. 

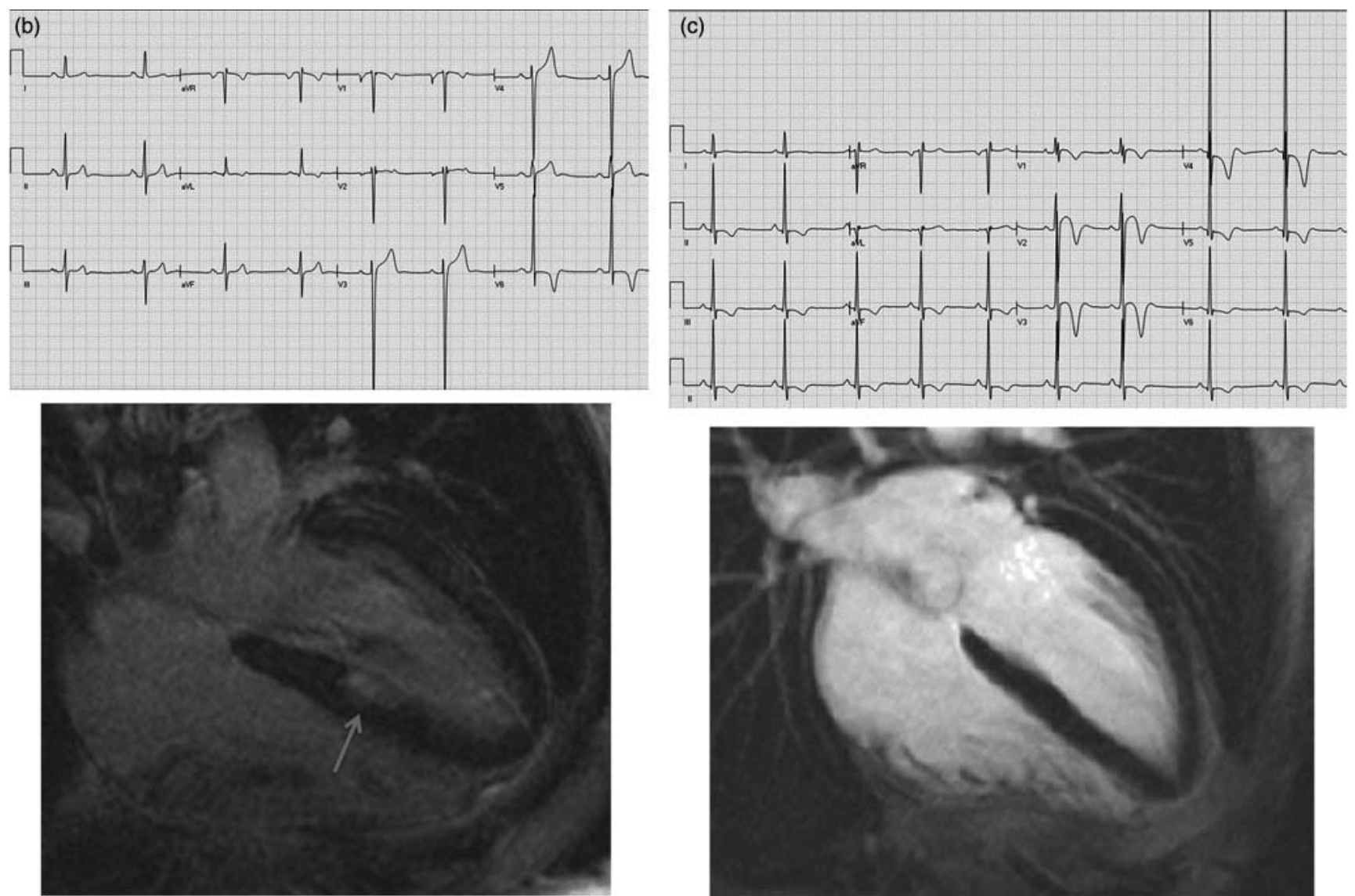

Figure 1 (Continued)

for those athletes with the largest BSA's, Black African ethnicity was associated with larger cardiac dimensions than either West-Asian or Caucasian ethnicity. Finally, in a sample of 836 athletes, 3 were diagnosed with a cardiomyopathy; $0.4 \%$ prevalence rate that in all cases, the ECG was vital for the initial identification and eventual diagnosis of the disease.
From four large-scale echocardiographic studies examining a total of 5053 elite athletes, ${ }^{4} 835$ only 134 athletes (2.7\%) demonstrated a maximal wall thickness greater than $12 \mathrm{~mm}$, with only a further 27 athletes $(0.5 \%)$ presenting $\mathrm{LVH}>13 \mathrm{~mm}$. However, out of these 5053 athletes the largest end of range BSA's in all four studies varied from 2.26 to $2.29 \mathrm{~m}^{2}$, with only one athlete from

Table 3 Cardiac structural variables compared between BSA categories (mean \pm SD; range)

\begin{tabular}{|c|c|c|c|}
\hline & Group 1 & Group 2 & Group 3 \\
\hline & BSA $>2.3 \mathrm{~m}^{2}(\mathrm{n}=99)$ & BSA $2-2.29 \mathrm{~m}^{2}(\mathrm{n}=243)$ & $B S A<1.99 \mathrm{~m}^{2}(\mathrm{n}=491)$ \\
\hline Aortic diameter (mm) & $30 \pm 2^{*}(25-35)$ & $28 \pm 2^{* *}(23-39)$ & $26 \pm 2(19-33)$ \\
\hline $\mathrm{LA}(\mathrm{mm})$ & $37 \pm 4^{*}(28-48)$ & $35 \pm 3^{* *}(26-47)$ & $32 \pm 4(21-42)$ \\
\hline LA area $\left(\mathrm{mm}^{2}\right)$ & $223 \pm 4^{*}(14-33)$ & $20 \pm 3^{* *}(13-31)$ & $18 \pm 4(10-30)$ \\
\hline LA volume (ml) & $66 \pm 17^{*}(23-103)$ & $58 \pm 15^{* *}(26-118)$ & $46 \pm 12(18-96)$ \\
\hline Right atrial area $\left(\mathrm{mm}^{2}\right)$ & $20 \pm 3^{*}(12 \pm 28)$ & $18 \pm 3^{* *}(12-28)$ & $15.6 \pm 5.8(8-26)$ \\
\hline Right ventricular internal diameter in diastole $(\mathrm{mm})$ & $22 \pm 5^{*}(14-40)$ & $19 \pm 4^{* *}(4-34)$ & $17 \pm 3(9-32)$ \\
\hline Interventricular septum thickness in diastole (mm) & $10 \pm 1 *(7-13)$ & $9 \pm 01 * *(7-12)$ & $9 \pm 1(6-12)$ \\
\hline Posterior wall thickness in diastole (mm) & $9 \pm 1 *(7-13)$ & $9 \pm 1 * *(6-11)$ & $8 \pm 1(5-11)$ \\
\hline LVID in diastole (mm) & $57 \pm 3^{*}(48-63)$ & $55 \pm 3^{* *}(42-65)$ & $52 \pm 4(40-62)$ \\
\hline LVID in systole (mm) & $40 \pm 5^{*}(26-50)$ & $39 \pm 4^{* *}(27-47)$ & $37 \pm 4(25-62)$ \\
\hline LV end diastolic volume (ml) & $155 \pm 30^{*}(88-271)$ & $133 \pm 23^{* *}(68-216)$ & $114 \pm 22(11-196)$ \\
\hline LVE end systolic volume (ml) & $50 \pm 12^{*}(22-111)$ & $45 \pm 10^{* *}(21-76)$ & $38 \pm 10(14-98)$ \\
\hline LV mass $(\mathrm{g})$ & $223 \pm 39 *(140-348)$ & $190 \pm 28 * *(123-286)$ & $157 \pm 30(66-241)$ \\
\hline
\end{tabular}

\footnotetext{
${ }^{*}$ Significant difference between BSA $>2.3 \mathrm{~m}^{2}$ and other two groups $(p<0.05)$.

${ }^{* *}$ Significant difference between BSA $2-2.29 \mathrm{~m}^{2}$ and BSA $<1.99 \mathrm{~m}^{2}(\mathrm{p}<0.05)$.

LA, left atrial diameter; LVID, left ventricular internal diameter.
} 
Figure 2 Relationship between the athlete's body surface area and their systolic blood pressure.

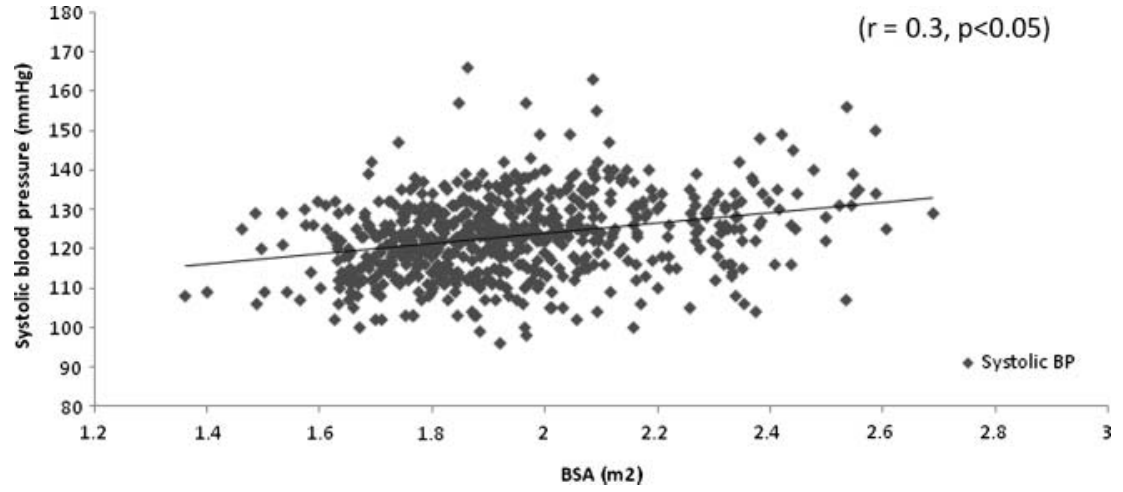

Table 4 Impact of ethnicity upon cardiac structure and function in athletes with a BSA $>2.3 \mathrm{~m}^{2}$ (mean $\pm S D$; range)

\begin{tabular}{|c|c|c|c|}
\hline & West-Asian & Black African & Caucasian \\
\hline & $\mathbf{N}=\mathbf{3 1}$ & $\mathrm{N}=45$ & $\mathbf{N}=\mathbf{2 3}$ \\
\hline Height $(\mathrm{cm})$ & $189 \pm 8(170-206)$ & $201 \pm 7(182-217)$ & $199 \pm 7(180-210)$ \\
\hline Body mass (kg) & $109 \pm 14(91-150)$ & $105 \pm 12(85-156)$ & $101 \pm 8(87-117)$ \\
\hline Body surface area $\left(\mathrm{m}^{2}\right)$ & $2.4 \pm 0.1(2.3-2.6)$ & $2.4 \pm 0.1(2.3-3.0)$ & $2.4 \pm 0.1(2.3-2.6)$ \\
\hline Aortic diameter (mm) & $30 \pm 2(25-33)$ & $30 \pm 2(26-35)$ & $30 \pm 2(26-34)$ \\
\hline $\mathrm{LA}(\mathrm{mm})$ & $37 \pm 4(30-45)$ & $37 \pm 4(28-45)$ & $37 \pm 4(29-48)$ \\
\hline $\mathrm{LA}$ area $\left(\mathrm{mm}^{2}\right)$ & $22 \pm 3(14-30)$ & $23 \pm 3(16-29)$ & $22 \pm 4(14-33)$ \\
\hline LA volume (ml) & $61 \pm 15(23-91)$ & $71 \pm 16^{* *}(36-103)$ & $60 \pm 18(31-98)$ \\
\hline Right atrial area $\left(\mathrm{mm}^{2}\right)$ & $19 \pm 4(12-28)$ & $21 \pm 3^{* *}(12-28)$ & $19 \pm 3(13-24)$ \\
\hline Interventricular septum thickness in diastole (mm) & $10 \pm 1(7-12)$ & $11 \pm 1 *(8-13)$ & $10 \pm 1(7-13)$ \\
\hline LVID in diastole (mm) & $60 \pm 1^{* * *}(48-60)$ & $57 \pm 1(50-63)$ & $58 \pm 1(54-63)$ \\
\hline Posterior wall thickness in diastole (mm) & $9 \pm 0.2(7-12)$ & $10 \pm 0.2^{*}(7-13)$ & $9 \pm 0.2(8-10)$ \\
\hline LVID in systole (mm) & $39 \pm 5(28-46)$ & $40 \pm 5(26-50)$ & $41 \pm 3(36-46)$ \\
\hline LV end diastolic volume (ml) & $147 \pm 32(88-236)$ & $157 \pm 24(109-209)$ & $161 \pm 36(120-271)$ \\
\hline LVE end systolic volume (ml) & $48 \pm 12(22-76)$ & $51 \pm 10(34-75)$ & $54 \pm 16(30-111)$ \\
\hline $\mathrm{LV}$ mass $(\mathrm{g})$ & $208 \pm 33(140-276)$ & $236 \pm 43^{* *}(146-348)$ & $217 \pm 27(164-266)$ \\
\hline
\end{tabular}

*Significant difference between Black athletes versus West-Asian and Caucasian athletes $(\mathrm{p}<0.05)$.

** Significant difference between Black athletes versus West-Asian athletes $(p<0.05)$.

${ }_{* * *}^{*}$ Significant difference between West-Asian athletes versus Caucasian athletes $(p<0.05)$.

LA, left atrial diameter; LVIDd, left ventricular internal diameter.

Whyte et $a l^{4}$ study presenting a BSA of $2.52 \mathrm{~m}^{2}$. This study presents 100 professional male athletes with a BSA $>2.3 \mathrm{~m}^{2}$ (mean 2.4 $\left.\pm 0.1 \mathrm{~m}^{2}\right)$. Only one athlete from this cohort demonstrated $\mathrm{LVH}>13 \mathrm{~mm}$, but he also exhibited a particular abnormal ECG suggestive of an inherited cardiac disease, and was eventually diagnosed with HCM via cardiac magnetic resonance. Of the remaining 99 asymptomatic athletes, 12 (12\%) had a wall thickness greater than $12 \mathrm{~mm}$ and $18(18 \%)$ had an LVIDd greater than $60 \mathrm{~mm}$. However, in the presence of a normal ECG, absence of systolic anterior motion of the anterior mitral valve leaflet causing LV outflow obstruction, an appropriately dilated LV, and normal diastolic function, a diagnosis of HCM was excluded in all athletes. This study suggests that irrespective of an athlete's enlarged BSA, the upper limit of physiological maximal wall thickness remains in the 13-16 mm range. Indeed, our data support the more conservative approach limits suggested by Whyte et al ${ }^{4}$ such that regardless of extreme body anthropometry, the physiological upper normal limits of LV wall thickness and LVIDd are 14 and $65 \mathrm{~mm}$, respectively.

Despite being referred for echocardiography due to a clinical suspicion of possible cardiac disease based on an abnormal ECG, family history or clinical evaluation, two studies are worthy of mention that support our data in 'big' athletes. Abernethy et al ${ }^{12}$ investigated 156 asymptomatic American Football (NFL) players and reported mean maximal wall thickness and LVIDd to be $11.2 \pm 0.2$ and $53 \pm 0.5 \mathrm{~mm}$, respectively. While Magalski et al ${ }^{11}$ observed that from 203 referred NFL athletes, 197 (97\%) demonstrated a maximal IVSd from 7 to $12 \mathrm{~mm}$, with six athletes (3\%) presenting an IVSd from 13 to $14 \mathrm{~mm}$. However, all 203 were considered not to have a cardiomyopic process due to no other echocardiographic abnormalities and normal Doppler inflow velocities.

It is well recognised that little account of body size is taken in the determination of 'apparently normal' cardiac dimensions in adult athletes, even though allometric scaling in the paediatric population is routine practice. ${ }^{36}$ Despite the strong relationships between BSA and multiple LV measures in the current study, absolute upper normal limits are still clinically relevant. It may be that scaling, via an appropriate method and scaling variable, maybe be of more clinical value in those athletes with smaller BSA's.

Recent data suggest that an athlete's ethnic origin may have a significant impact on their cardiovascular response to exercise. $^{13} 3537$ Despite no significant difference in BSA between ethnicities in the $>2.3 \mathrm{~m}^{2}$ cohort of athletes, Black African athletes presented significantly greater wall thicknesses, and resultant LV masses, than West-Asian and Caucasian athletes. It should be noted that regardless of ethnicity and the extreme BSA of this cohort, the established upper limits of cardiac structure and function are applicable to all three ethnicities. Previous data from our group have demonstrated that a minority 
(3\%) of Black athletes (mean BSA $2.1 \mathrm{~m}^{2} ; 9$ from 300) may present physiological $\mathrm{LVH} \geq 15 \mathrm{~mm} .{ }^{34}$ The present data set of 219 Black African athletes from a broad range of BSA's did not find an athlete with a normal ECG presenting a maximal wall thickness greater than $13 \mathrm{~mm}$. A limitation of the present study is that a data set of 46 Black African with a BSA $>2.3 \mathrm{~m}^{2}$ maybe too small to ascertain if this ethnicity with extreme anthropometry requires the upper limits of physiological LVH to be raised to $15 \mathrm{~mm}$; in spite of demonstrating significantly greater wall thicknesses and masses that their West-Asian and Caucasian counterparts. Interestingly, Basavarajaiah et a ${ }^{35}$ study demonstrated that basal and exercise-related BP responses in both Black and Caucasian athletes did not differ and could not explain the increased magnitude of LVH in Black athletes. At the time, we suggested that a combination of genetic, ${ }^{38}$ endocrine and haemodynamic factors ${ }^{39}$ probably accounts for the increased LVH in black athletes. Yet to date, no data have been published to confirm this postulation. Second, while professional basketball, handball and volleyball players were recruited, substantiation of the upper limits of physiological $\mathrm{LVH}$ is required in the small minority of athletes with extreme BSA's who compete in sports that induce the greatest amounts of cardiac remodelling; namely rowing, cycling, cross-country skiing, biathlon. Nevertheless, this will once again prove problematic for the Black African ethnicity whose participation in these endurance sports is limited.

Regardless of these limitations, our data support the clinical utility of ECG in the initial identification of athletes suspected of harbouring an inherited cardiac disease. The present study diagnosed one athlete with a mild variant of apical HCM via cardiac magnetic resonance, following an abnormal ECG suggestive of an inherited cardiac disease. This was in spite of a normal echocardiogram (maximal LV wall thickness of $8 \mathrm{~mm}$ ). In conclusion, marked repolarisation changes, ST depression, pathological $\mathrm{Q}$ waves and multiple ventricular ectopic's are a great concern, even when cardiac dimensions are within accepted limits.

In conclusion, irrespective of an athlete's extreme anthropometrical dimensions and ethnicity, the physiological upper normal limits of LV wall thickness and LV internal diameter during diastole due to intensive and sustained physical activity are 14 and $65 \mathrm{~mm}$, respectively. Moreover, even when matched for extreme BSA $\left(>2.3 \mathrm{~m}^{2}\right)$, Black African athletes present significantly greater wall thicknesses and resultant LV masses than Arabic and Caucasian athletes.

\section{What this study adds}

- Regardless of extreme body surface area (BSA), no asymptomatic athlete with a negative family history of sudden cardiac death and a normal ECG presented a maximal wall thickness $>14 \mathrm{~mm}$.

- Established upper limits for physiological cardiac hypertrophy of $14 \mathrm{~mm}$ for maximal wall thickness and $65 \mathrm{~mm}$ for left ventricular internal diameter during diastole are appropriate, irrespective of an athlete's BSA.

- We identified one athlete with a cardiomyopathy with normal wall thicknesses on echocardiography but abnormal cardiac magnetic resonance. The ECG remains key and should guide follow-up management. Marked repolarisation changes, ST depression, pathological 0 waves and multiple ventricular ectopic's are a great concern, even when cardiac dimensions are within accepted limits on echocardiography.
Acknowledgements Lead by Mrs Caroline Buckler, we acknowledge the sterling efforts of Aspetar's athlete screening team in the data collection; Nelly Khalil, Pascale Tahtouh, Farah Demachkieh, Manal Al Tarany, Zahia Al Khoury, Ezzoubair Moustaati and Diana El Chamaa.

Contributors MGW designed the study, OS undertook all echocardiography, NRR wrote the preliminary draft of the manuscript and all authors supplied comments and corrections, MGW is the guarantor. All authors read and approved the final manuscript.

Competing interests None.

Ethics approval Shafallah Medical Genetics Centre.

Provenance and peer review Not commissioned; externally peer reviewed.

\section{REFERENCES}

1. Whyte GP, George K, Nevill A, et al. Left ventricular morphology and function in female athletes: a meta-analysis. Int J Sports Med 2004;25:380-3.

2. Pluim BM, Zwinderman $A H$, van der Laarse $A$, et al. The athlete's heart. $A$ meta-analysis of cardiac structure and function. Circulation 2000;101:336-44.

3. Pelliccia A, Maron BJ, De Luca R, et al. Remodeling of left ventricular hypertrophy in elite athletes after long-term deconditioning. Circulation 2002;105:944-9.

4. Whyte GP, George K, Sharma S, et al. The upper limit of physiological cardiac hypertrophy in elite male and female athletes: the British experience. Eur J Appl Physiol 2004;92:592-7.

5. Corrado D, Basso C, Thiene G. Essay: sudden death in young athletes. Lancet 2005;366(Suppl 1):S47-8.

6. Baggish AL, Wood MJ. Athlete's heart and cardiovascular care of the athlete: scientific and clinical update. Circulation 2011;123:2723-35.

7. Pelliccia A, Maron BJ, Spataro A, et al. The upper limit of physiologic cardiac hypertrophy in highly trained elite athletes. N Engl J Med 1991;324:295-301.

8. Basavarajaiah S, Wilson M, Whyte G, et al. Prevalence of hypertrophic cardiomyopathy in highly trained athletes: relevance to pre-participation screening. $J$ Am Coll Cardiol 2008;51:1033-9.

9. Batterham AM, George KP, Whyte G, et al. Scaling cardiac structural data by body dimensions: a review of theory, practice, and problems. Int J Sports Med 1999;20:495-502.

10. George KP, Birch KM, Pennell DJ, et al. Magnetic-resonance-imaging-derived indices for the normalization of left ventricular morphology by body size. Magn Reson Imaging 2009;27:207-13.

11. Corrado D, Pelliccia A, Bjornstad HH, et al. Cardiovascular pre-participation screening of young competitive athletes for prevention of sudden death: proposal for a common European protocol. Consensus Statement of the Study Group of Sport Cardiology of the Working Group of Cardiac Rehabilitation and Exercise Physiology and the Working Group of Myocardial and Pericardial Diseases of the European Society of Cardiology. Eur Heart J 2005;26:516-24.

12. Abernethy WB, Choo JK, Hutter AM Jr. Echocardiographic characteristics of professional football players. J Am Coll Cardiol 2003:41:280-4.

13. Magalski A, Maron BJ, Main ML, et al. Relation of race to electrocardiographic patterns in elite American football players. J Am Coll Cardiol 2008;51:2250-5.

14. Dubois D, Dubois EF. A formula to estimate the approximate surface area if height and weight be known. Arch Intern Med 1916;17:863-71.

15. Wilson MG, Chatard JC, Carre F, et al. Prevalence of electrocardiographic abnormalities in West-Asian and African male athletes. Br J Sports Med 2012:46:341-7.

16. Wilson MG, Hamilton B, Sandridge AL, et al. Differences in markers of cardiovascular disease between professional football players of West-Asian and Black African descent. J Sci Med Sport 2011;15:266-71

17. Corrado D, Pelliccia A, Heidbuchel $H$, et al. Recommendations for interpretation of 12-lead electrocardiogram in the athlete. Eur Heart J 2010;31:243-59.

18. Tajik AJ, Seward JB, Hagler DJ, et al. Two-dimensional real-time ultrasonic imaging of the heart and great vessels. Technique, image orientation, structure identification, and validation. Mayo Clin Proc 1978;53:271-303

19. Sahn DJ, DeMaria A, Kisslo J, et al. Recommendations regarding quantitation in M-mode echocardiography: results of a survey of echocardiographic measurements. Circulation 1978;58:1072-83.

20. Devereux RB. Detection of left ventricular hypertrophy by M-mode echocardiography. Anatomic validation, standardization, and comparison to other methods. Hypertension 1987; 9:II19-26.

21. Maron BJ. Structural features of the athlete heart as defined by echocardiography. J Am Coll Cardiol 1986;7:190-203.

22. Sharma S, Maron BJ, Whyte G, et al. Physiologic limits of left ventricular hypertrophy in elite junior athletes: relevance to differential diagnosis of athlete's heart and hypertrophic cardiomyopathy. J Am Coll Cardiol 2002;40:1431-6.

23. Maron BJ, Pelliccia A, Spirito P. Cardiac disease in young trained athletes. Insights into methods for distinguishing athlete's heart from structural heart disease, with particular emphasis on hypertrophic cardiomyopathy. Circulation 1995;91:1596-601. 
24. Lewis JF, Spirito P, Pelliccia A, et al. Usefulness of Doppler echocardiographic assessment of diastolic filling in distinguishing "athlete's heart" from hypertrophic cardiomyopathy. Br Heart J 1992;68:296-300.

25. Basavarajaiah S, Makan J, Naghavi SH, et al. Physiological upper limits of left atrial diameter in highly trained adolescent athletes. J Am Coll Cardiol 2006;47:2341-2; (author reply 2342).

26. Pelliccia A, Maron BJ, Di Paolo FM, et al. Prevalence and clinical significance of left atrial remodeling in competitive athletes. J Am Coll Cardiol 2005;46:690-6.

27. Klues HG, Roberts WC, Maron BJ. Morphological determinants of echocardiographic patterns of mitral valve systolic anterior motion in obstructive hypertrophic cardiomyopathy. Circulation 1993;87:1570-9.

28. Savage DD, Seides SF, Clark CE, et al. Electrocardiographic findings in patients with obstructive and nonobstructive hypertrophic cardiomyopathy. Circulation 1978;58:402-8.

29. Maron BJ, Wolfson JK, Ciro E, et al. Relation of electrocardiographic abnormalities and patterns of left ventricular hypertrophy identified by 2-dimensional echocardiography in patients with hypertrophic cardiomyopathy. Am J Cardiol 1983;51:189-94.

30. Monserrat L, Elliott PM, Gimeno JR, et al. Non-sustained ventricular tachycardia in hypertrophic cardiomyopathy: an independent marker of sudden death risk in young patients. J Am Coll Cardiol 2003;42:873-9.

31. Sharma $\mathbf{S}$, Elliott $P$, Whyte $G$, et al. Utility of cardiopulmonary exercise in the assessment of clinical determinants of functional capacity in hypertrophic cardiomyopathy. Am J Cardiol 2000;86:162-8.
32. Sharma S, Elliott PM, Whyte $\mathrm{G}$, et al. Utility of metabolic exercise testing in distinguishing hypertrophic cardiomyopathy from physiologic left ventricular hypertrophy in athletes. J Am Coll Cardiol 2000;36:864-70.

33. Maron MS. Clinical utility of cardiovascular magnetic resonance in hypertrophic cardiomyopathy. J Cardiovasc Magn Reson 2012;14:13.

34. Elliott PM, Poloniecki J, Dickie S, et al. Sudden death in hypertrophic cardiomyopathy: identification of high risk patients. J Am Coll Cardiol 2000;36:2212-18.

35. Basavarajaiah S, Boraita A, Whyte $G$, et al. Ethnic differences in left ventricular remodeling in highly-trained athletes relevance to differentiating physiologic left ventricular hypertrophy from hypertrophic cardiomyopathy. J Am Coll Cardiol 2008;51:2256-62

36. Dewey FE, Rosenthal D, Murphy DJ Jr, et al. Does size matter? Clinical applications of scaling cardiac size and function for body size. Circulation 2008:117:2279-87.

37. Rawlins J, Carre F, Kervio G, et al. Ethnic differences in physiological cardiac adaptation to intense physical exercise in highly trained female athletes. Circulation 2010;121:1078-85

38. Barley J, Blackwood A, Miller M, et al. Angiotensin converting enzyme gene I/D polymorphism, blood pressure and the renin-angiotensin system in Caucasian and Afro-Caribbean peoples. J Hum Hypertens 1996;10:31-5

39. Ekelund LG, Suchindran CM, Karon JM, et al. Black-white differences in exercise blood pressure. The Lipid Research Clinics Program Prevalence Study. Circulation 1990:81:1568-74. 